\title{
Enxerto gengival livre para correção de defeitos de tecido mole previamente a cirurgias reconstrutivas
}

Free gingival graft for correction of soft tissue defects prior to reconstructive surgeries Injerto gingival gratuito para la correccion de defectos de tejidos blandos antes de la cirugía reconstructiva Anabelle DIAS-RIBEIRO ${ }^{1}$

Julliana Cariry Palhano FREIRE ${ }^{2}$

Jaqueline Oliveira BARRETO ${ }^{3}$

Eduardo DIAS-RIBEIRO ${ }^{4}$

Ronaldo LIRA-JÚNIOR

Diogo José Barreto de MENEZES ${ }^{6}$

${ }^{1}$ Cirurgiã-Dentista clínica privada, João Pessoa, Paraíba, Brasil

${ }_{2}^{2}$ Departamento de Odontologia, Universidade Estadual da Paraíba (UEPB), Campina Grande, Paraíba, Brasil

${ }^{3}$ Departamento de Odontologia do Centro de Saúde e Tecnologia Rural, Universidade Federal de Campina Grande, UFCG, 58708-110 Patos, Paraíba, Brasil

${ }^{4}$ Departamento de Cirurgia e Traumatologia Bucomaxilofacial, Universidade Federal da Paraíba, UFPB, João Pessoa, Paraíba, Brasil

${ }^{5}$ Departamento de Periodontia, Universidade do Estado do Rio de Janeiro (UERJ), Rio de Janeiro, Rio de Janeiro, Brasil

${ }^{6}$ Departamento de Periodontia e Implantodontia, Centro Universitário de João Pessoa (UNIPÊ-JP), João Pessoa, Paraíba, Brasil

\section{Resumo}

A anatomia do tecido mole peri-implantar é semelhante à do dente natural, uma vez que apresenta epitélio juncional e tecido conjuntivo. O selamento peri-implantar é estabelecido pela mucosa ceratinizada que previne a migração apical da margem gengival, mantendo a arquitetura tecidual e estética vermelha ao redor dos implantes osseointegráveis. O presente trabalho objetivou relatar um caso clínico de reconstrução de tecido mole previamente a cirurgia óssea reconstrutiva para a instalação de implante osseointegrável. Após a reconstrução do tecido mole observou-se que houve um satisfatório ganho de altura e espessura tecidual. Foi obtido um volume tecidual suficiente para regularização do zênite gengival e considerável volume de mucosa ceratinizada foi obtida previamente a cirurgia reconstrutiva.

Descritores: Implantes Dentários; Periodontia; Reabilitação Bucal.

\section{Abstract}

The anatomy of the peri-implant soft tissue is similar to the natural tooth, since it presents junctional epithelium and connective tissue. The peri-implant sealing is established by keratinized mucosa that prevents the apical migration of the gingival margin, keeping the tissue architecture and red aesthetics around dental implants. This study aims to report a case of soft tissue reconstruction prior to reconstructive bone surgery for the installation of osseointegrated implant. After the reconstruction of soft tissue was observed that there was a satisfactory gain in time and tissue thickness, tissue was obtained a sufficient volume to stabilize the gingival zenith and considerable volume of keratinized mucosa was previously obtained reconstructive surgery.

Descriptors: Dental Implants; Periodontics; Mouth Rehabilitation.

\section{Resumen}

La anatomía del tejido blando periimplantario es similar a la del diente natural, ya que tiene epitelio de unión y tejido conectivo. El sellado periimplantario está establecido por la mucosa queratinizada que evita la migración apical del margen gingival, manteniendo la estética roja y la arquitectura del tejido alrededor de los implantes osteointegrados. Este estudio tuvo como objetivo informar un caso clínico de reconstrucción de tejidos blandos antes de la cirugía ósea reconstructiva para la instalación de implantes osteointegrados. Después de la reconstrucción del tejido blando, se observó que hubo una ganancia satisfactoria en altura y grosor del tejido. Se obtuvo un volumen de tejido suficiente para regular el cenit gingival y se obtuvo un volumen considerable de mucosa queratinizada antes de la cirugía reconstructiva.

Descriptores: Implantes Dentales; Periodoncia; Rehabilitación Bucal.

\section{INTRODUÇÃO}

Atualmente, a reabilitação oral com próteses implanto-suportadas vem crescendo dentro da rotina ambulatorial da odontologia. De fato, seu planejamento e execução, é desafio para o cirurgiãodentista, pois este procedimento está diretamente relacionado com a qualidade de vida do sujeito, uma vez que envolve o fator funcional e estético, os quais são fundamentais para a satisfação final do paciente $^{1-3}$.

Nessa perspectiva, as instalações de implantes dentais devem ter uma atenção para estética do tecido mole, uma vez que é imprescindível para um resultado harmônico gengiva-implante. Desta maneira, espera-se um contorno gengival idêntico ou similar ao dente contralateral ou estar em harmonia com o dente/prótese adjacente ${ }^{4}$.

Além disso, uma dimensão vertical inadequada do tecido peri-implantar vestibular pode levar a recessão, tamanho diferente da coroa e abutment ou ombro do implante visíveis. Já a perda de volume do tecido na direção horizontal pode causar sombra na região ou um perfil reto ou côncavo, facilitando o acúmulo de alimento e a retenção microbiana que causa inflamação gengival, podendo levar até insucesso do procedimento ${ }^{5,6}$.

Vários métodos têm sido propostos para a obtenção de quantidade adequada de mucosa ceratinizada. $\mathrm{O}$ enxerto gengival livre pode ser uma alternativa apropriada em áreas de tecido queratinizado insuficiente, apresentando boa previsibilidade $^{7-9}$.

O presente artigo relata um caso de utilização de enxerto gengival livre com o objetivo de aumentar a mucosa ceratinizada prévia a cirurgia reconstrutiva.

\section{CASO CLÍNICO}

Paciente do sexo masculino, 33 anos de idade, ASA I, procurou consultório particular queixando-se de desconforto estético na região anterior de maxila. Na anamnese, o mesmo relatou ser alérgico ao Ácido-Acetil-Salicílico, Sulfa e Penicilina. Observou-se no exame intrabucal uma coroa metalocerâmica sobre implante cônico, de $5 \mathrm{x}$ $15 \mathrm{~mm}$ (Conexão Sistemas de Prótese ${ }^{\circledR}$, São Paulo, SP, Brasil) na região do elemento $21 \mathrm{com}$ perda da 
tábua óssea vestibular, profundidade à sondagem de $7 \mathrm{~mm}$, adelgaçamento da gengiva inserida e desnivelamento do zênite gengival (Figura 1). Por meio de uma tomografia computadorizada por feixe cônico foi verificado imagem sugestiva de perda óssea na face vestibular, vestibularização do implante e ausência de sinais de inflamação ou infecção (Figuras 2 e 3). Após o diagnóstico optou-se juntamente com o paciente pela remoção do implante dentário. O mesmo foi esclarecido quanto aos riscos, vantagens e desvantagens do plano de tratamento apresentado e sua aceitação se deu mediante sua assinatura no termo de consentimento livre e esclarecido.

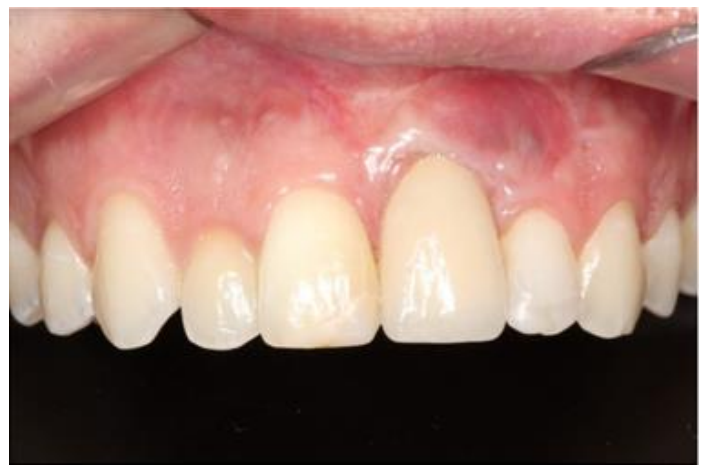

Figura 1: Caso inicial.

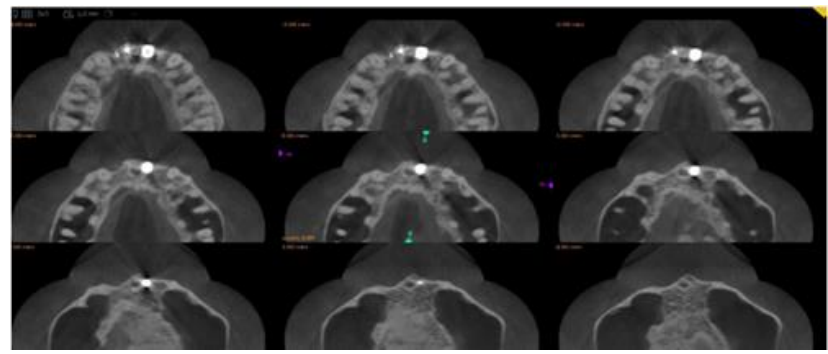

Figura 2: Tomografia computadorizada.

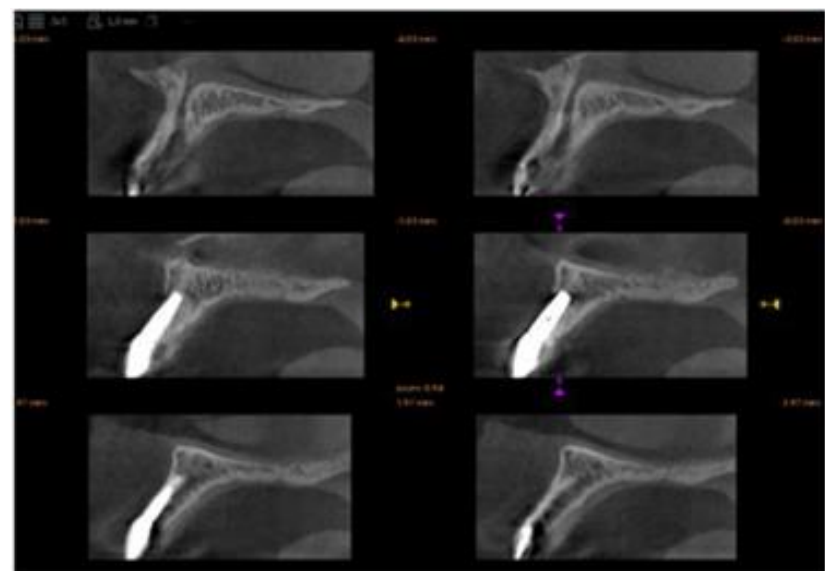

Figura 3: Tomografia computadorizada.

O procedimento cirúrgico iniciou-se com a anestesia da região, por meio da técnica infiltrativa (vestibular e palatina), utilizando-se para tal o cloridrato de articaína 4\% com adrenalina 1:100.000 (Nova DFL ${ }^{\circledR}$, Rio de Janeiro, RJ, Brasil). A coroa foi removida com auxílio de caneta de alta rotação montada com broca diamantada e transmetal, sob irrigação abundante (Figura 4). Em seguida, o implante foi removido com a chave de inserção manual do sistema Conexão (Conexão Sistemas de Prótese $^{\circledR}$, São Paulo, SP, Brasil) por meio do contratorque (Figuras 5, 6 e 7).

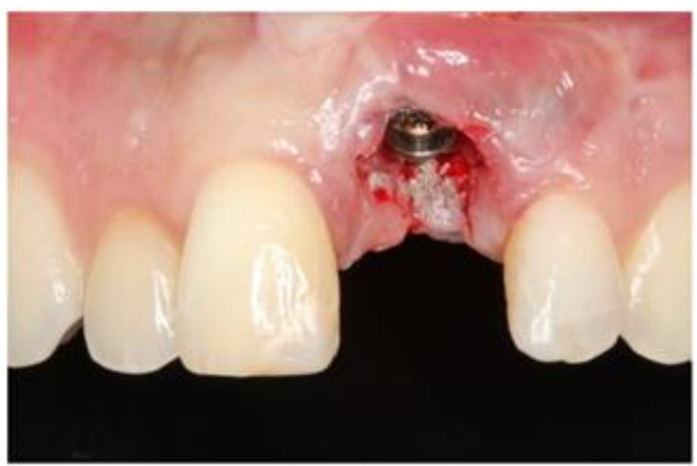

Figura 4: Remoção da coroa metalocerâmica.

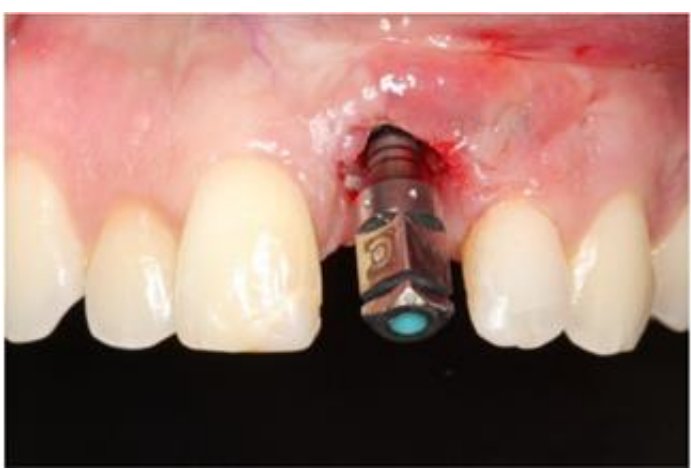

Figura 5: Colocação da chave de inserção no implante.

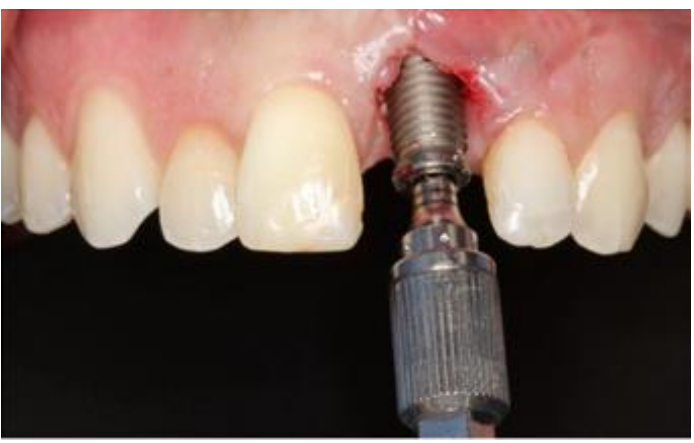

Figura 6: Remoção do implante.

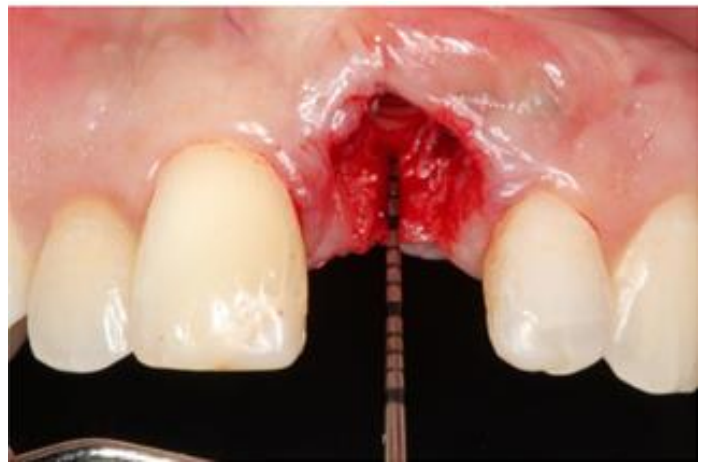

Figura 7: Aspecto tecidual após a remoção do implante.

Em seguida, foi confeccionado um template com o papel do fio de sutura, para determinar o diâmetro do enxerto gengival livre misto (enxerto gengival livre com pedículo de tecido conjuntivo) proveniente do palato duro (área doadora). Desta forma, foi feita incisão, descolamento, transposição e fixação do enxerto gengival livre misto na área receptora, por meio de suturas simples interrompidas com fio de sutura reabsorvível (Vicryl ${ }^{\circledR}$, Ethicon, 
Johnson\&Johnson, São Paulo, SP, Brasil). Este procedimento tem como objetivo condicionar $\mathrm{o}$ tecido gengival previamente à cirurgia reconstrutiva (Figuras 8 a 13). Foi realizado um enceramento e a partir dele confeccionado um provisório até a substituição por uma prótese implanto-suportada em etapa posterior (Figuras 14 a 18). Em pós-operatórios de 20 e 40 dias ficou evidente o bom aspecto das abordagens cirúrgicas e o ganho gengival seja em altura como espessura, bem superior quando da presença do implante em posição.

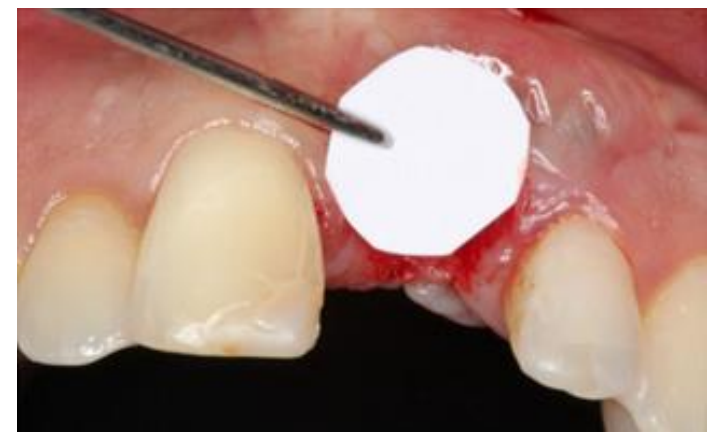

Figura 8: Template para mensuração da área doadora.

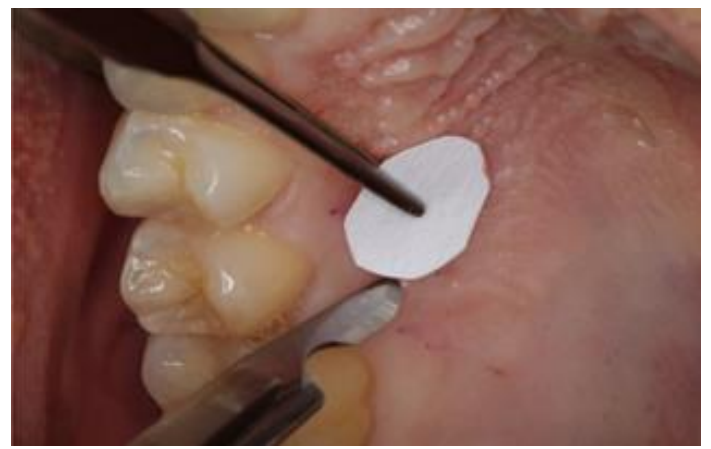

Figura 9: Delineamento da incisão de enxerto gengival livre misto.

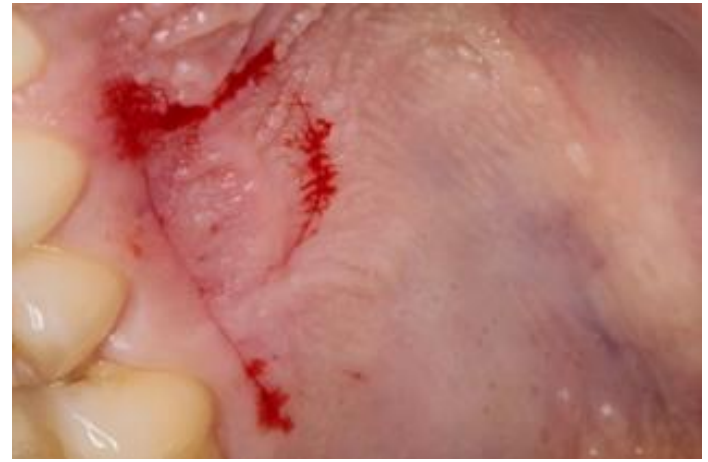

Figura 10: Incisão para remoção de enxerto gengival livre misto.

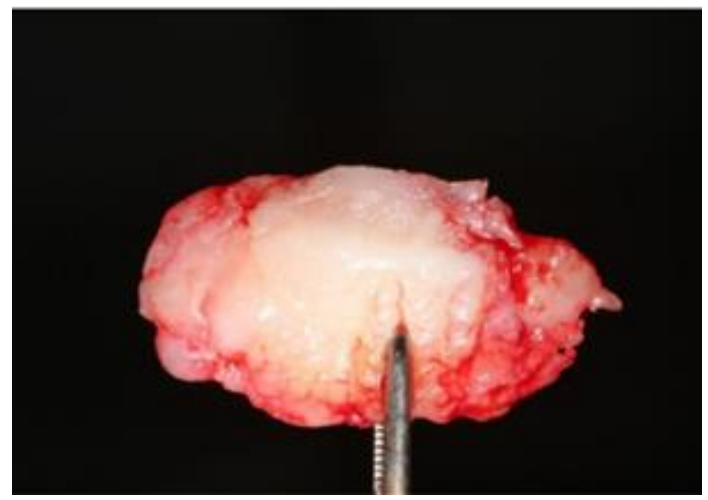

Figura 11: Remoção de enxerto gengival livre misto.

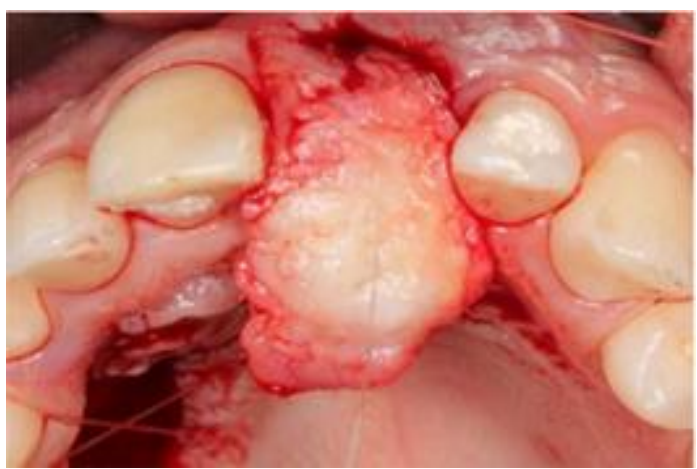

Figura 12: Adaptação inicial do enxerto gengival livre misto no leito receptor.

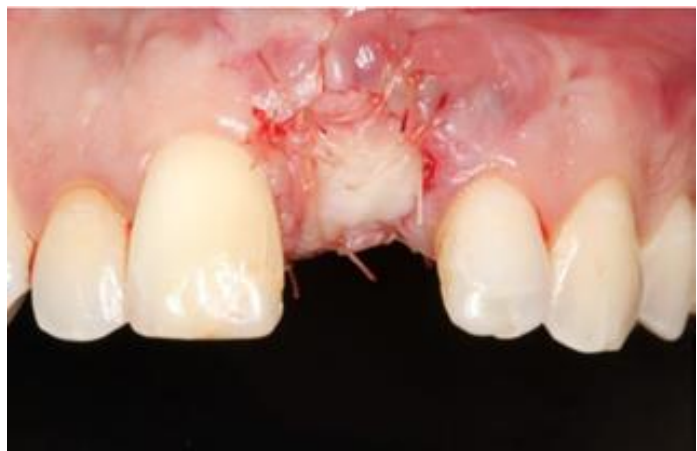

Figura 13: Adaptação e sutura do enxerto gengival livre misto no leito receptor.

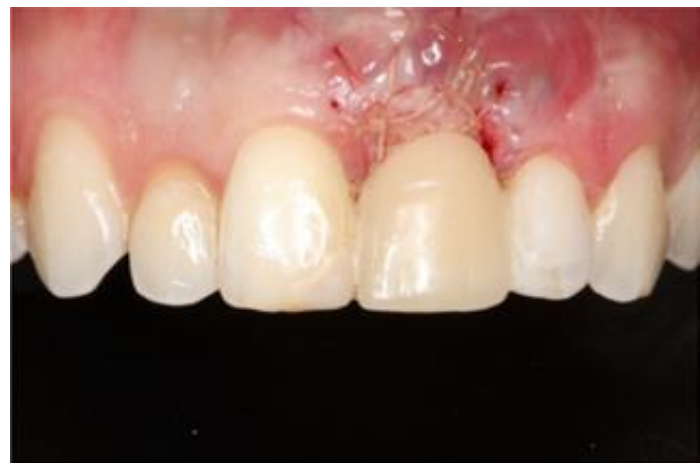

Figura 14: Instalação de prótese adesiva provisória.

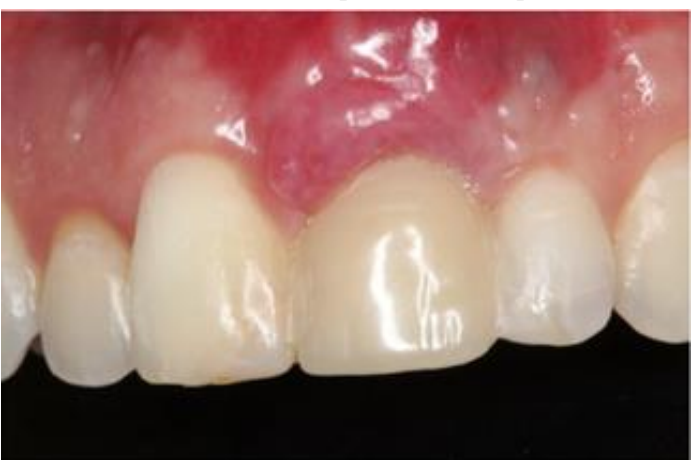

Figura 15: Aspecto da cicatrização tecidual após 20 dias (visão frontal).

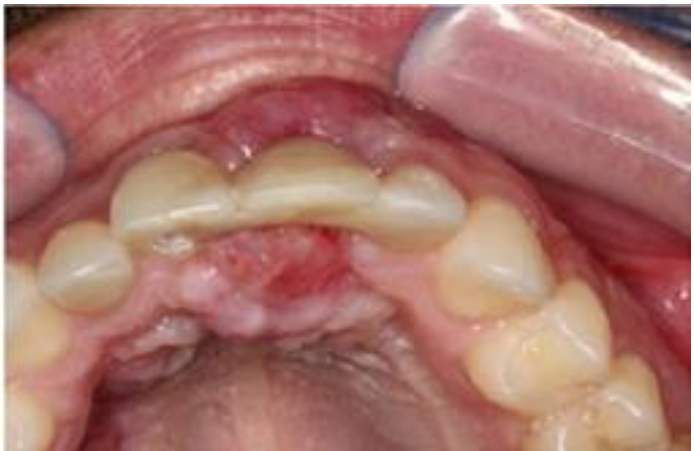

Figura 16: Aspecto da cicatrização tecidual após 20 dias (visão oclusal) 


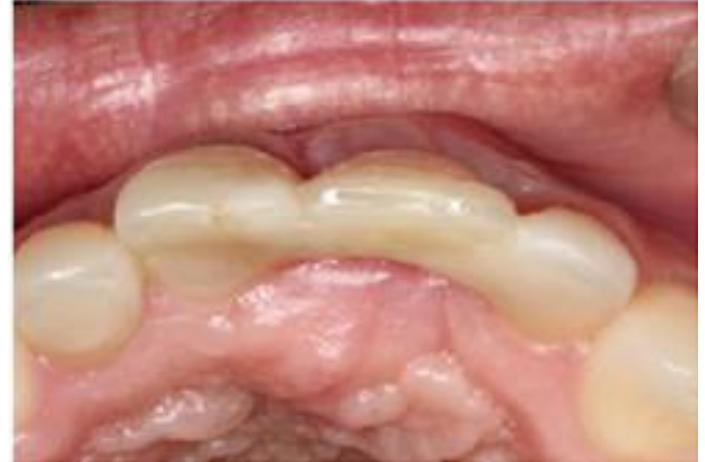

Figura 17: Aspecto da cicatrização tecidual após 40 dias (visão frontal).

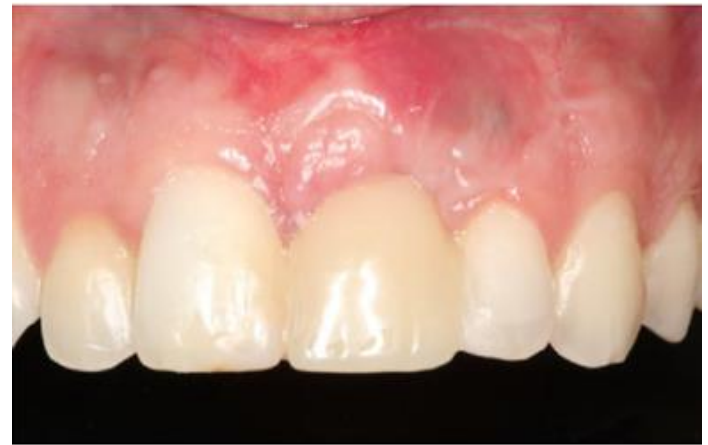

Figura 18: Aspecto da cicatrização tecidual após 40 dias (visão oclusal).

DISCUSSÃO

Desde 1972, Lang e Loe já preconizavam uma quantidade de gengiva queratinizada como necessidade para saúde gengival, uma vez que a inflamação persiste em áreas menores de $2,0 \mathrm{~mm}$, corroborando com estudos mais recentes ${ }^{10-12}$. Todavia, outros autores discordam que isso influencie na sobrevida em longo prazo dos implantes ${ }^{13-14}$.

Alguns autores demonstram que não só a quantidade, mas a largura e espessura do tecido queratinizado interfere no sucesso dos implantes osseointegrados ${ }^{6,15}$. Para isso, vários métodos têm sido propostos para essa adequada obtenção, sendo os retalhos posicionados apicalmente e lateralmente, enxertos gengivais livres ou enxertos de tecido conjuntivo são os mais comumente empregados ${ }^{7}$.

No caso clínico apresentado, em função da perda óssea na parede vestibular, com consequente vestibularização do implante, o comprometimento estético do trabalho já se mostrava presente assim como a recessão gengival. Diante disso, optou-se pelo o recobrimento com enxerto livre de uma região do palato, cujos resultados pós-operatórios foram satisfatórios para estética e saúde dos tecidos periimplantares, corroborando com os achados de outros autores ${ }^{1,4,7,8,10}$. De acordo com $\mathrm{Fu}$ et al. ${ }^{16}$, embora com maior desconforto pós-operatório e tempo de cirurgia, o enxerto autógeno é padrão-ouro com maior satisfação do paciente e estética.

O caso clínico apresentado reveste-se de relevância clínica, uma vez que a preservação da gengiva ceratinizada em quantidade satisfatória evita a migração apical do tecido que receberá uma nova reabilitação protética, impedindo o colabamento tecidual, além de estar intimamente ligada à saúde peri-implantar facilitando algo considerado aqui como o fator principal: controle efetivo da placa bacteriana e assim prolongando a vida útil dos dispositivos protéticos futuros ${ }^{10,17}$.

CONCLUSÃO

Com esta técnica observou-se um volume tecidual suficiente para regularização do zênite gengival, um significativo aumento dos tecidos moles em altura e espessura e após a cirurgia reconstrutiva, o reparo tecidual proporcionou uma ampla faixa de mucosa ceratinizada.

\section{REFERENNCIAS}

1. Mutthineni RB, Dudala RB, Ramisetty A. Esthetic root coverage with double papillary subepithelial connective tissue graft: a case report. Case Rep Dent. 2014;2014:509319.

2. Peñarrocha MA, Carrillo C, Boronat A,Martí EM. Level of satisfaction in patients with maxillary mull-arch fixed protheses: zigomatic versus convencional implants. Int $\mathbf{J}$ Oral Maxillofac Implants. 2007; 22(5):769-73.

3. Ponsi J, Lahti S, Rissanen H, Oikarinen K. Change in subjective oral health after single dental implant treatment. Int $\mathbf{J}$ Oral Maxillofac Implants. 2011;26(3):571-77.

4. Man Y, Wang Y, Qu Y, Wang P, Gong P. A palatal roll envelope technique for peri-implant mucosa reconstruction: a prospective case series study. Int J Oral Maxillofac Surg. 2013; 42(5):660-65.

5. Schneider D, Grunder U, Ender A, Hämmerle $\mathrm{CH}$, Jung RE. Volume gain and stability of periimplant tissue following bone and soft tissue augmentation: 1-year results from a prospective cohort study. Clin Oral Implants Res. 2011;22(1):28-37.

6. Evans CD, Chen ST. Esthetic outcomes of immediate implant placements. Clin Oral Implants Res. 2008;19(1):73-80.

7. Grover HS, Yadav A, Yadav P, Nanda P. Free gingival grafting to increase the zone of Keratinized tissue around implants. Int $\mathrm{J}$ Oral Implant Clinical Res. 2011;2(2):117-20.

8. Almeida JM, Novaes VN, Faleiros PL, Macarimi VC, Bosco AF, Theodoro LH et al. Aumento de gengiva ceratinizada em mucosa peri-implantar. Rev odontol UNESP. 2012; 41(5):365-69.

9. Langer B, Langer L. Overlapped flap: a surgical modification for implant fixture installation. Int $\mathbf{J}$ Periodontics Restorative Dent. 1990;10(3):208-15.

10. Raghoebar GM, Meijer HJA, van Minnen B, Vissink A. Immediate Reconstruction of Failed Implants in the Esthetic Zone Using a Flapless Technique and Autogenous Composite Tuberosity Graft. J Oral Maxillofac Surg. 2018;76(3):528-33. 
11. Chung DM, Oh TJ, Shotwell JL, Misch CE, Wang HL. Significance of keratinized mucosa in maintenance of dental implants with different surfaces. J Periodontol. 2006;77(8):1410-20.

12. Park JC, Yang KB, Choi Y, Kim YT , Jung UW, Kim CS et al. A simple approach to preserve keratinized mucosa around implants using a prefabricated implant-retained stent: a report of two cases. J Periodontal Implant Sci. 2010; 40(4):194-200.

13. Wennström JL, Bengazi F, Lekholm U. The influence of the masticatory mucosa on the periimplant soft tissue condition. Clin Oral Implants Res. 1994;5(1):1-8.

14. Bengazi F, Wennström JL, Lekholm U. Recession of the soft tissue margin at oral implants. A 2-year longitudinal prospective study. Clin Oral Implants Res. 1996;7(4):303-10.

15. Bouri A Jr, Bissada N, Al-Zahrani MS, Faddoul F, Nouneh I. Width of keratinized gingiva and the health status of the supporting tissues around dental implants. Int J Oral Maxillofac Implants. 2008;23(2):323-26.

16. Fu JH, Su CY, Wang HL. Esthetic soft tissue management for teeth and implants. J Evid Based Dent Pract. 2012;12(3 Suppl):129-42.

17. Marquez IC. The role of keratinized tissue and attached gingiva in maintaining periodontal/periimplant health. Gen Dent. 2004;52(1):74-9.

\section{CONFLITO DE INTERESSES}

Os autores declaram não haver conflitos de interesse.

\section{AUTOR PARA CORRESPONDÊNCIA}

\section{Eduardo Dias Ribeiro}

eduardo_ufpb@hotmail.com

Universidade Federal da Paraíba (UFPB) - Centro de Ciências da Saúde CCS Disciplina de Cirurgia Bucomaxilofacial I Campus I - Lot. Cidade Universitaria, PB, 58051-900
Submetido em 02/10/2019

Aceito em 12/03/2020 